FENOMENA PEMAHAMAN DAN PENERAPAN HAKIKAT MAKNA KATA KEJAHATAN DAN PELANGGARAN DALAM PERKEMBANGAN HUKUM

Hamsir

$\mathrm{OO}$

IJTIHAD DAN URGENSINYA

Usman Jafar

$\longrightarrow 0$

PARTISIPASI POLITIK DALAM KONSEPSI TEORI PILIHAN RASIONAL JAMES S COLEMAN

Nila Sastrawati

THAHARAH LAHIR DAN BATIN DALAM AL-QURAN

(Penafsiran terhadap Qs. Al-Muddatsir/74:4 dan Qs. Al-Maidah/5:6)

Ahmad Mujahid, Haeriyyah

$-10$

STUDI KRITIS PERNIKAHAN BAWAH UMUR PERSPEKTIF UUP NO. 16 TAHUN 2019 DAN GENDER ANALISIS

Sippah Chotban

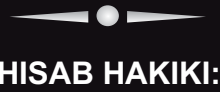

Metode IImiah Penentuan Awal Bulan Kamariyah

Alimuddin

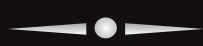

POLIGAMI DALAM SOROTAN

(Kajian Kitab-kitab Tafsir Modern/Kontemporer)

Halimah B

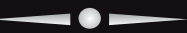

ADAT AMPIKALE:

Asuransi Ala Masyarakat Bugis di Kecamatan Pammana Kabupaten Wajo

Hadi Daeng Mapuna

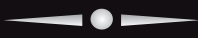

MEDIA SOSIAL DAN DAMPAKNYA TERHADAP PERCERAIAN

Sohrah

זע: HIMPUNAN ILMUWAN DAN SARJANA SYARIAH INDONESIA 


\section{$\underline{\text { Al-Risalah }}$}

Jurnal Ilmu Syariah dan Hukum

\section{DAFTAR ISI}

FENOMENA PEMAHAMAN DAN PENERAPAN HAKIKAT MAKNA KATA

KEJAHATAN DAN PELANGGARAN DALAM PERKEMBANGAN HUKUM

Hamsir

IJTIHAD DAN URGENSINYA

Usman Jafar

PARTISIPASI POLITIK DALAM KONSEPSI TEORI PILIHAN

RASIONAL JAMES S COLEMAN

Nila Sastrawati

THAHARAH LAHIR DAN BATIN DALAM AL-QURAN

(Penafsiran terhadap Qs. Al-Muddatsir/74:4 dan Qs. Al-Maidah/5:6)

Ahmad Mujahid, Haeriyyah

STUDI KRITIS PERNIKAHAN BAWAH UMUR PERSPEKTIF UUP NO. 16

TAHUN 2019 DAN GENDER ANALISIS

Sippah Chotban

HISAB HAKIKI: Metode Ilmiah Penentuan Awal Bulan Kamariyah

Alimuddin

POLIGAMI DALAM SOROTAN (Kajian Kitab-kitab Tafsir

Modern/Kontemporer)

Halimah B 
PERILAKU SEKSUAL TRANSGENDER

254-275

(Studi Komparatif Hak Asasi Manusia Antara Perspektif The Universal

Declaration of Human Right dan The Cairo Declaration of Human Right)

Adriana Mustafa

ADAT AMPIKALE: Asuransi Ala Masyarakat Bugis di Kecamatan Pammana

Kabupaten Wajo

276-285

Hadi Daeng Mapuna

MEDIA SOSIAL DAN DAMPAKNYA TERHADAP PERCERAIAN

286-296

Sohrah 


\title{
IJTIHAD DAN URGENSINYA
}

\author{
Usman Jafar \\ Fakultas Syariah dan Hukum UIN Alauddin Makassar
}

\section{Abstract}

This study is intended to determine the role and urgency of ijtihad as a method of extracting and discovering Islamic law from its main sources, the Qur'an and Sunnah. This method cannot be separated from the context of the era which is always changing and developing along with the emergence of various new problems that have no legal provisions in the text.

The results achieved through the ijtihad method show that Islamic law becomes elastic and develops so that it effectively becomes a solution in dealing with various problems as a result of changes and developments of the times.

Keywords: Ijtihad and its Urgency

\section{A. PENDAHULUAN}

Ijtihad merupakan sendi utama dalam pembangun dan penggalian hukum Islam dari sumber utamanya, Al-Qur'an dan Sunnah Nabi Muhammad saw,. Hal ini dipahami karena Al-Qur'an membawa syari'at (perundangundangan), ia merupakan hukum Tuhan yang sebagiannya memiliki ajaran substansi atau dalam kajian figh disebut ajaran stawabit, yaitu ajaran yang tidak dapat diubah dan diubah, ia berlaku secara absolut dan universal, ia tidak terpengaruh oleh perkembangan dan perubahan zaman, karena semua peraturannya telah dirumuskan begitu rupa sehingga tidak ada satupun di antaranya yang pernah berlawanan dengan tabiat manusi dan tuntutan masyarakat. Hal ini disebabkan semata-mata karena semua peraturanperaturan yang telah ditetapkan Tuhan adalah mengikat segi-segi kehidupan manusia yang hakikat sifatnya tidak akan berubah dan diubah.

Hukum Tuhan yang dapat diterapkan kepada semua tingkatan dan keadaan dari perkembangan manusia, menunjukkan bahwa peratutanperaturannya pada tarap pertama meliputi asas-asas yang bersifat umum, dan pada tarap kedua mengadakan perundang-undangan terperinci terhadap halhal yang tak terpengaruh oleh perubahan-perubahan yang disebabkan oleh perubahan dan perkembangan manusia. Apabila ada perundang-undangan atau nash yang teperinci, maka ia pastilah berhubungan dengan segi-segi kehidupan perseorangan dan kemasyarakatan yang bebas dari semua perubahan yang disebabkan oleh masa dan perubahan zaman. Sebaliknya apabila perubahan-perubahan itu tidak boleh tidak untuk kemajuan manusia, misalnya dalam soal politik, pemerintahan, teknologi, sosial ekonomi, dan lainlain, syari'ah tidak menentukan hukum yang terperinci, melainkan hanya meletakkan asas umum yang bersifat global. Dan kekosongan inilah yang dapat 
diisi oleh ijtihad, dalam pengertian menjadi wilayah ijtihadiya. ${ }^{1}$

Hal yang demikian ini, dipahami karena risalah Islam adalah untuk rahmat bagi alam dan nikmat bagi manusia. Bagaimana Islam menuntun kehidupan manusia agar sesuai dengan risalahnya, maka umat Islam perlu merumuskan dan menegakkan suatu sistem kebudayaan Islam yang mampu menciptakan kebaikan bagi manusia seluruhnya. Suatu sistem kebudayaan yang harus mengalami perkembangan dan kemajuan sebagaimana watak dari kebudayaan itu sendiri yang selalu seirama dengan kondisi dan tuntutan zaman, tetapi tetap berpijak pada nilai-nilai Islam atau tetap sejalan dengan nafas Islam. Dalam menghadapi kehidupan yang serba berubah itu dan menjawab setiap tantangan dan perubahan zaman, Islam meletakkan suatu doktrin pemikiran disebut ijtihad. Kalau Al-Qur'an dan Sunnah sebagai dua sumber asasi ajaran Islam, maka ijtihad sebagai alat penggeraknya, tanpa ijtihad, kedua sumber tersebut akan menjadi statis dan kaku.

Hasil ijtihad adalah memperkuat risalah Islam yang abadi. Ia menjadi bukti bagi manusia bahwa Islam memberikan peluang dan kesempatan untuk berijtihad sehingga selalu membuka pintu bagi para itelektual untuk berijtihad dalam upaya mencari dan menemukan hukum. Hal ini menunjukkan bahwa berijtihad itu penting bahkan diperintahkan.

Bagi umat Islam, ijtihad adalah suatu kebutuhan dasar, bukan saja ketika nabi sudah tidak ada, tetapi bahkan ketika nabi masih hidup. Nabi tidak saja mengizinkan tetapi menyambut dengan gembira campur haru begitu mendengar tekad Muazd bin Jabal untuk berijtihad dalam hal-hal yang tidak diperoleh ketentuannya secara jelas dalam Al-Qur'an maupun dalam hadis. Apabila di masa nabi saja ijitihad sudah bisa dilakukan, maka sepeninggal beliau tentu jauh lebih mungkin dan diperlukan. Di kalangan umat Islam manapun tidak ada perintah yang sungguh-sungguh menyatakan ijtihad haram dan harus benar-benar dihindari. Dalam konteks ini, Nadiyah Syarif mengatakan bahwa setiap periode harus ada seorang atau beberapa orang yang mampu berperan sebagai mujtahid. ${ }^{2}$

\section{B. PENGERTIAN IJTIHAD DAN KEDUDUKANNYA}

Ijtihad berasal dari kata kerja, ijtihada - yajtahidu yang berarti pengerahan segala kemampuan untuk mengerjakan sesuatu yang sulit, atau biasa juga bermakna bersungguh-sungguh dalam bekerja dengan segenap kemampuan yang ada. ${ }^{3}$ Perkataan ini tentu saja tidak akan dipergunakan untuk sesuatu yang tidak mengandung kesulitan. Sayyid Muhammad Al-Huduri di dalam kitabnya Ushul Al-Fiqh, mengatakan bahwa secara literal ijtihad adalah berusaha sekuat tenaga membawa batu giling dan tidak dikatakan berusaha

${ }^{1}$ Lihat Sayyed Muhammad Musa, Al-Ijtihad wa Madza Hujjatuna Ilaihi fi Hadza al- 'Asr. (Mesir dar al-Kutub Al-Haditsah, T.th.,), h. 18.

${ }^{2}$ Nadiyah Syarif, Al-Ijtihad fi Al-Islam Ushuluhu Ahkamuhu, (Bairut:Muassasah Risalah, 1991), h. 213.

${ }^{3}$ Muhammad, Abu Zahrah, Ushul Fiqh, (Kairo: Dar Al-Fikr, t.th., ), h. 301. 
bersungguh-sungguh dalam membawa biji sawi. ${ }^{4}$ Di kalangan para ulama Ushul terjadi polarisasi dalam mendefinisikan ijtihad tersebut, Wabah alZuhaili misalnya mendefinisikan bahwa ijtihad adalah usaha yang sungguhsungguh untuk menemukan hukum-hukum syari' dari dalil-dalilnya yang terperinci dalam syari'at. ${ }^{5}$ Hal yang sama juga dikemukakan Abdul Wahab Khallaf, ijtihad adalah daya kemampuan untuk menghasilkan hukum syara' dari dalil-dalilnya yang terperinci. Sedangkan bagi mayoritas ulama ushul dalam memhami ijtihad adalah pengerahan segenap kesanggupan oleh ahli fiqh atau mujtahid untuk memperoleh hukum syara'. Dengan demikian ijtihad tidak untuk menguatkan hukum syara' yang statusnya qat'i, tetapi kepada hukum-hukum syara' yang sifatnya dzanniyah dan semacamnya. ${ }^{6}$

Ketetapan adanya ijitihad yang merupakan pokok syari'at dapat diketahui baik dengan isyarat ataupun dengan tegas dalam ajaran agama, baik dalam AlQur'an maupun dalam Sunnah. Dalam Al-Qur'an misalnya, Tuhan mengatakan "Sesungguhnya pada yang demikian itu terdapat tanda-tanda (kebesaran Allah) bagi kaum yang memikirkan" (QS. Al-Ra'du: 3, Al-Ruum: 21, dan Al-Zumar: 42). Demikian pula Al-Qur'an surah Al-Hazar: 2 “. . . maka ambillah (kejadian itu) untuk menjadi pelajaran bagi orang-orang yang mempunyai pandangan".

Ayat-ayat tersebut mengisaratkan kepada manusia agar menggunakan pikiran dan akal serta mengambil i'tibar.

\section{URGENSI IJITHAD}

Adalah suatu kenyataan, bahwa kita selalu dihadapkan pada berbagai persoalan yang membutuhkan ketentuan hukumnya. Para ulama terdahulu telah bekerja dengan sungguh-sungguh untuk masa dan generasinya. Mereka menyelesaikan berbagai persoalan yang terjadi disekitarnya dan bahkan banyak manfaatnya sampai kepada kita melalui kitab-kitab fiqh yang mereka susun dan karya-karya yang mereka tulis. Akan tetapi masa terus berubah dan lapangan hidup manusia terus berkembang dan maju, akibatnya banyak peristiwa-peristiwa baru yang belum pernah terjadi sebelumnya. Terhadap peristiwa-peristiwa tersebut menjadi challenge buat Islam, menuntut jawaban dan sikap positif. Sudah barang tentu kita tidak bisa diam dengan alasan bahwa para ulama tidak pernah membicarakan masalah tersebut atau menyalahkan mereka karena tidak pernah membicarakannya. Mereka tidak salah, para ulama dan sarjana Islam dahulu telah berbuat dan berjasa untuk zamannya dan bahkan untuk zaman kita sekarang ini. Karena dari merekalah kita belajar tentang sejarah dan ilmu walaupun sering ada persamaan masalah pada masa dulu dan sekarang yang mereka jawab tetapi belum pasti jawaban mereka sesuai dengan saat kita sekarang, kerena perbedaan adat istiadat, kondisi, pengaruh pikiran dan perasaan yang melingkupi ulama yang

\footnotetext{
${ }^{4}$ Sayyid Muhammad Al-Huduri, Ilmu Ushul Fiqh, (Bairut: Dar Al-Fikr, 1995), h. 123.

${ }^{5}$ Wahbah Al-Zuhali, Al-Wasith fi Ushul al-Fikih al-Islam, (Damaskus: Dar Al-Kitab, 1978), h. 529.

${ }^{6}$ Abdul Wahab Khallaf, Ushul Al-Fiqh, (Kuwait: Dar al-Kuwaitiyah, 1969), h. 234.
} 
menjawab masalah itu. Inilah sebabnya mengapa kita harus melakukan ijtihad sampai detik ini.

Pada dasarnya setiap muslim diharuskan untuk berijtihad dalam semua bidang hukum syari'at, asal dia sudah memenuhi keriteria dan syarat sebagai seorang mujtahid. Para ulama membagi hukum melakukan ijtihad dengan tiga macam yaitu:

1. Wajib Ain, yaitu bagi orang yang dimintai fatwa hukum mengenai suatu peristiwa yang terjadi, dan ia khawatir peristiwa itu lenyap tanpa ada kepastian hukumnya atau ia sendiri mengalami suatu peristiwa dan ia ingin mengetahui hukumnya;

2. Wajib Kifayah, yaitu bagi orang yang memintai fatwa hukum mengenai suatu peristiwa yang tidak dikhawatirkan lenyap peristiwa itu, sedang selain dia masih terdapat mujtahid-mujtahid lainnya. Maka apabila kesemua mujtahid itu tidak ada yang melakukan ijtihad, maka mereka berdosa, tetapi bila ada seorang dari mereka memberikan fatwa hukum maka gugurlah tuntutan ijtihad atas diri mereka.;

3. Sunnah, yaitu apabila melakukan ijtihad mengenai masalah-masalah yang belum atau tidak terjadi. ${ }^{7}$

Muchtar Kamal, menyatakan bahwa setiap ijtihad harus diorientasikan pada tajdid (pembaharuan), karena setiap periode mempunyai ciri tersendiri sehingga menentukan perubahan hukum. ${ }^{8}$ Sedang Abdul Syakur dalam "Muslimatus Subur" mengharuskan ijtihad selalu mengacu pada perubahan dan setiap perubahan itu mengacu pada pembaharuan yang bertujuan untuk mencapai kebenaran. ${ }^{9}$

Dalam konteks pembaharuan sebagaimana disebutkan di atas, Nabi Muhammad saw, menyatakan bahwa Allah mengutus pada umat ini setiap penghujung periode -- 100 tahun - seorang pembaharu yang akan memperbaharui agamanya. Walaupun demikian tidak semua hasil ijtihad itu merupakan pembaharuan bagi ijtihad yang lama, sebab ada kalanya hasil ijtihad yang baru sama dengan hasil ijtihad yang lama, bahkan sekalipun berbeda hasil ijtihad baru itu tidak dapat merubah status ijtihad yang lama. Hal ini sesuai dengan yang dikemukakan Yusuf Al-Qardhawi, bahwa ijtihad itu tidak dapat dibatalkan dengan ijtihad awal. ${ }^{10}$

Lebih lanjut urgensi ijtihad dapat dilihat dari fungsi ijtihad itu sendiri yang terbagi dalam tiga macam, yaitu:

1. Fungsi al-ruju' atau al-i'adah (kembali), yaitu mengembalikan ajaran-ajaran Islam kepada sumber pokoknya, yakni Al-Qur'an dan Al-Sunnah Shahihah dari segala interpretasi yang dimungkinkan kurang relevan;

\footnotetext{
${ }^{7}$ Masyfuk, Zuhdi, Ijtihad dan Problematikanya dalam memasuki Abad XV H (Surabaya: Bina Hukum, 1981), h. 137-138.

${ }^{8}$ Muchtar, Kamal, Ushul Fiqh, Jilid II, (Yogyakarta: Dana Bhakti Wakaf, 1995), h. 23.

9 Nadiyah Syarif Umari, Al-Ijtihad fi Al-Islam, Ushuluhu, Ahkamuhu, Afaquhu, (Bairut: Muassdengan asah Risalah, 1991), h. 199-200.

${ }^{10}$ Yusuf Al-Qardhawi, Al-Ijtihad Al-Mu'ashir baina Al-Indlibatht wa al-Infirathi (Cairo: Dar alTanzi wa al-Nasyr al-Islamiyah, 1993), h. 200.
} 
2. Fungsi al-ihya' (kehidupan), yaitu menghidupkan kembali bagian-bagian dari nilai dan semangat ajaran Islam agar mampu menjawab dan menghadapi tantangan zaman, sehingga Islam mampu berfungsi sebagai furqan, hudan dan rahmat lil 'alamin;

3. Fungsi al-ibanah (pembenahan), yaitu membenahi ajaran-ajaran yang telah dijtihadi oleh ulama terdahulu yang dimungkinkan adanya kekurang sesuaian menurut konteks zaman, keadaan dan tempat yang kini kita hadapi. ${ }^{11}$

Beranjak dari pemikiran tentang urgrnsi ijtihad di atas, dapatlah diambil beberapa hikmah yang terkandung dari pelaksanaan ijtihad, antara lain:

1. Menghidupkan pikiran manusia untuk berkembang dan berpikir dengan seksama, karena tanpa ijtihad atau tidak diperbolehkan ijtihad, akan melemahkan kemampuan berpikir dan hal ini berarti juga mengakibatkan kemandulan berpikir, hal ini jelas bertentangan dengan ajaran Islam;

2. Mengatasi dan memecahkan kesulitan-kesulitan yang ditemui di dalam masyarakat atau kehidupan manusia, karena berdasarkan kenyataan, semakin banyak persoalan-persoalan baru yang timbul, semakin menghendaki adanya ijtihad atau pemikiran baru;

3. Memelihara kepentingan-kepentingan esensial dalam kehidupan manusia, seperti memelihara keselamatan agama, jiwa, akal, keturunan atau kehormatan, harta, dan memelihara kepentingan-kepentingan lainnya;

4. Sebagai alat pencari kebenaran terhadap penyelesaian perkara yang timbul, baik berdasarkan dalil yang ada nashnya maupun yang tidak ada nashnya;

5. Jika ijtihad hidup dan berkembang, maka hukum Islam akan menjadi berkembang dan dinamis pula;

6. Melalui ijtihad dibuktikan bahwa ajaran Islam itu tetap relevan pada setiap waktu dan tempat.

\section{KEDUDUKAN HUKUM IJTIHAD}

Hukum hasil ijtihad seorang mujtahid tidaklah mengikat dan tidak pula menjadi hujjah bagi seluruh umat Islam. Karena itu tidak seorangpun wajib mengikuti dan bertindak sesuai dengan hukum ijtihad itu. Sebab masalah ataupun kasus yang telah diijtihadi dan telah ditetapka hukumnya oleh seorang mujtahid, masih tetap terbuka untuk menjadi sasaran ijtihad. Karena hukum ijtihadi itu didasarkan atas dalil-dalil syar'i yang bukan qath'i dan hasil ijma'. Karena itu hukum ijtihad itu bisa berbeda karena perbedaan penalaran dan pengkajian serta situasi dan kondisi yang mengitari para mujtahid. Dalam konteks ini qaidah ushul mengatakan: "Taghaiyyurul al-ahkam bi taghaiyyiru alzaman wala makanatu wal ahwalu" (perubahan hukum berdasarkan perubahan zaman, waktu dan keadaan).

Namun hukum ijtihad itu mengikat dan menjadi hujjah bagi mujtahid yang bersangkutan. Ia wajib melakukan hasil ijtihadnya secara konsekwen, selama ia belum merubah pendapatnya. Dan ia juga tidak boleh meninggalkan

${ }^{11}$ Muhaimin dkk, Dimensi-dimensi Studi Islam, (Surabaya: Karya Abditama, 194), h. 190-191 
hukum ijtihadnya lalu bertaqlid pada mujtahid lain yang yang berbeda pendapatnya mengenai masalah yang sama, karena masing-masing mujtahid menggunakan dasar atau asas yang sama dalam menetapkan hukum ijtihad yakni sama-sama bersifat hipotesis.

Demikian pula hukum ijtihad mengikat dan menjadi hujjah bagi orangorang yang meminta fatwa kepada mujtahid tentang suatu masalah, sebab mazhab orang yang meminta fatwa tersebut mengikat mazhab muftinya. Karena itu ia harus mengikuti pendapat muftinya menurut ulama ushul fiqh. ${ }^{12}$

Hukum ijtihad bagi mujtahid yang bersangkutan maupun bagi mujtahid lainnya pada hakikatnya belum dapat dipastikan bahwa hukum itu adalah hukum syara'. Hukum ijtihadi menjadi hukum syara' hanya menurut anggapan atau dugaan mujtahid yang bersangkutan. Karena itu ulama ushul menegaskan bahwa mujtahid tidak membuat hukum dari dia sendiri sekalipun ia menggunakan metode ijtihad dengan ra'yu (reassoning). Sebab ia sebenarnya hanya menggali untuk menemukan hukum syara' menurut dugaannya, dengan cara memperhatikan petunjuk-petunjuk dan isyarat-isyarat yang telah diberikan oleh syara' (Allah dan Rasul-Nya) guna memperoleh hukum syara' itu sendiri. ${ }^{13}$

Hukum ijtihadi masih terbuka bagi mujtahid yang bersangkutan dan juga bagi mujtahid yang lainnya untuk dikaji ulang. Dan apabila seoarng mujtahid berijtihad mengenai masalah yang menimpa dirinya, lalu ia menetapkan hukum ijtihadinya, dan bertindak sesuai dengan hukum ijtihadinya. Tetapi bila kemudian ia berubah pendapat maka ia harus meninggalkan hukum ijtihadinya yang pertama dan mengambil hukum ijtihadinya yang kedua (yang baru) setelah ia menganggap salah atau keliru hukum hasil ijtihadinya yang pertama. Misalnya ia berijtihad tentang masalah izin wali bagi wanita yang menikah, dan menurut ijtihadnya boleh kawin dengan wanita tanpa izin walinya. Kemudian laki-laki tersebut mengawani wanita tanpa izin walinya sesuai dengan hukum ijtihadinya, tetapi kemudian hukum ijtihadinya berubah setelah ia mengadakan ijtihad ulang, maka ia harus mengubah hukum ijtihadinya yang pertama dengan hukum ijtihadinya yang kedua. Dan sebagai konsekwensi ijtihadnya, maka ia harus mufarraqah (pisah) dengan istrinya kemudian melakukan akad nikah baru dengan izin walinya.

\section{E. RUANG LINGKUP IJTIHAD}

Para ulama ushul telah sepakat bahwa ruang lingkup ijtihad adalah pada ayat-ayat yang bersifat $d z a n n i$, karena sebagian dari materi-materi hukum dalam Al-Qur'an dan Sunnah sudah berbentuk diktum yang aotentik, yakni tidak mengandung pengertian lain atau sudah diberi interpretasi yang autentik oleh sunnh itu sendiri. Di samping itu juga ada sebahagian di antaranya yang

\footnotetext{
${ }^{12}$ Al-Amidi, Al-Ahkam, juz !V, ( Cairo: Dar Al-Nahdara al-Arabiyah, 1986), h. 306

13 Muhammad Salam, Madzkur, Al-Madkhal li Al-Fiqh Al-Islami, (Cairo: Dar Al-Nahdlah AlArabiyah), 1960), h. 292-293
} 
sudah memperoleh kesepakatan bulat serta diperlakukan secara umum dan mengikat semua pihak atau berdasarkan ijma'.14

Adapun nash-nash qath'i yang sudah jelas serta tidak memerlukan interpretasi lagi, tidak perlu diijtihadkan, dalam arti bukanlah menjadi wilayah ijtihad. Masalah-masalah yang merupakan ruang lingkup ijtihad adalah sebagai berikut:

1. Hukum-hukum yang dibawa oleh nash-nash yang dzanni baik dari segi wurudnya maupun dari segi pengertian (dalalahnya) yaitu hadis ahad. Sasaran ijtihad ini adalah dari segi sanad dan pensahihannya dengan hukum yang akan dicari itu.

2. Hukum yang dibawa oleh nash yang qath'i tetapi dalalahnya dzanni, maka obyek ijtihadnya adalah segi dalalahnya saja.

3. Nash yang wurudnya dzanni tetapi dalalahnya qath'i, maka obyek ijtihadnya adalah pada sanad, kesahihan serta kesinambungannya;

4. Tidak ada nash dan ijma akan obyek ijtihadnya hanya dilakukan dengan segenap metode dan cara.

\section{F. KESIMPULAN}

Ijtihad menurut mayoritas ulama ushul adalah pengerahan segenap kesanggupan oleh seorang ahli fiqh atau mujtahid untuk memperoleh pengertian tingkat $d z a n$ mengenai hukum syara'.

Ijtihad merupakan sendi Islam yang ketiga sesudah Al-Qur'an dan Sunnah. Dan begitu urgennya keberadaan ijtihad kiranya tidaklah dapat dilepaskan dari konteks zaman yang selalu berubah dan dengan bermunculannya berbagai masalah baru yang belum ada ketetapan hukumnya.

Adanya anggapan bahwa pintu ijtihad telah tertutup hanya akan memberi kesan bahwa hukum Islam itu statis dan tidak berkembang. Sebaliknya dengan terbukanya pintu ijtihad menunjukkan bahwa hukum Islam itu bersifat elastis dan bisa disesuaikan dengan perubahan dan perkembangan jaman dan kondisi.

${ }^{14}$ Huzaimah Tahido, Yanggo, Pengantar Perbandingan Madzhab, (Ciputat: Logos Wacana Ilmu, 1997), h. 6. 


\section{DAFTAR PUSTAKA}

Husein, Ibrahim, Ijtihad dalam Sorotan, Bandung, Mizan, 1991

Khallaf, Abdul Wahhab, Ushul Ak-Figh, Kuwait, Dar Al-Kuwaitiyah, 1969

Madzkur, Muhammad Sallam, Al-Madkhal li Al-Figh Al-Islami, Cairo, Dar AlNahdlah Al-Arabiyah, 1960

Muchtar, Kamal dkk, Ushul Figh, Jilid II, Yogyakarta, Dana Bhakti Wakaf, 1995

Muhaimin dkk, Dimensi-dimensi Studi Islam, Surabaya, Karya Abditama, 1994

Al-Qardhawi, Yusuf, Ijtihad Al-Mua'ashir bain Al-Indlibathl wa Al-Infirathl, Cairo, Dar Al-Tanzi wa Al-Basyr Al-Islamiyah, 1993

Al-Saayis, Syaikh Muhammad Ali, Nasy'at Al-Figh Al-Ijtihadi wa Athwaruhu, Alih vahasa oeh M. Ali Hasan, Jakarta, Raja Grafindo Oersada, 1995

Ash-Shiddiqy, M. Hasbi, Pengantar Ilmu Fiqh, Jakarta, Bulan Bintang, 1993

Umari, Nadiyah, Al-Ijtihad fi Al-Islam, Ushuluhu, Afaquhu, Bairut, Muassasah Risalah, 1991

Yanggo, Huzaemah Tahido, Pengantar Perbandingan Madzhab, Ciputat, Logos Wacana Ilmu, 1997

Zuhaili, Wahbah, Al-Wasith fi Ushul Al-Fiqh Al-Islami,t,tp., t.th

Zuhdi, Masyfuk, Ijtihad dan Problematikanya dalam Memasuki Abad XV $H$. Surabaya, Bina Ilmu

-------, Pengantar Hukum Syari'ah, Jakarta, CV. Haji Masaguna

Muhammad Musa, Sayyed, Al-Ijtihad wa Madza Hujjatuna Ilaihi fi Hadza al-'Asr. Mesir dar al-Kutub Al-Haditsah, T.th.

Muhammad Al-Huduri, Sayyid, Ilmu Ushul Figh, Bairut: Dar Al-Fikr, 1995

Al-Amidi, Al-Ahkam, juz !V, Cairo: Dar Al-Nahdara al-Arabiyah, 1986 